\title{
Islamic Theology And Rasionalism: Analisis Pemikiran Sutan Takdir Alisyahbana
}

\author{
Abdul Kohar \\ Fakultas Ushuludin dan Pemikiran Islam UIN Sunan Kalijaga \\ qohhar.succes@gmail.com
}

\begin{abstract}
This paper explores the thoughts of Sutan Takdir Alisyahbana (STA). STA is referred to as a cultural practitioner, because it discusses more the cultures that enter Indonesia, such as Indian, Hindu, Buddhist, Islamic and native Indonesian culture, even it also discusses western culture. He also wrote a lot such as poetry, novels, philosophy books and he was among the first to make Indonesian terms, so he was called a writer. This research is a type of library research (library research) by presenting qualitative-interpretative data. The purpose of this study is to reveal the fact that the religion of Islam in Indonesia is a religion that does not dichotomize between the reality supported by invoices and spiritual reality because Islam today is deeply engrossed in the history of the development of Islam in the time of the Prophet Muhammad, also today Islam is shackled with religious myths, so as to be able to resolve Islam in Indonesia, it cannot develop and is anti-Western rationality. STA thinking is rooted in the humanist understanding that developed in Europe from the Renaissance to the rise of new-positivism. Its humanism is built on human liberation from the shackles of mythology and religion.
\end{abstract}

Keywords: Teologi Islam, Rasionalis, S. Takdir Alisyahbana

\begin{abstract}
Abstrak
Tulisan ini mengupas tentang pemikiran Sutan Takdir Alisyahbana (STA). STA disebut seorang budayawan, karena ia banyak membahas tentang budaya yang masuk di Indonesia, seperti kebudayaan India, Hindu, Budha, Islam dan kebudayaan Indonesia asli, bahkan ia juga mempelajari kebudayaan barat. Ia banyak juga menulis seperti puisi, sajak, novel, buku filsafat dan ia termasuk orang yang pertamakali membuat istilah-istilah bahasa Indonesia, sehingga ia disebut sastrawan. Penelitian ini merupakan jenis penelitian pustaka (library research) dengan penyajian data kulatitatif-interpretatif. Tujuan penelitian ini untuk mengungkapkan bahwa kebudayaan Islam di Indonesia ini merupakan kebudayaan yang tidak mendikotomikan antara realitas otentik (faktual) dengan realitas ruhani (ketenangan jiwa), karena Islam hari ini sangat terlena dengan keindahan sejarah Islam dimasa Rasulullāh SAW, juga Islam hari ini terbelenggu dengan mitos-mitos agama, sehingga dapat mengakibatkan Islam di Indonesia tidak bisa berkembang dan anti terhadap rasionalitas barat. Pemikiran STA berakar dalam paham humanis yang berkembang di Eropa sejak Renaissance hingga bangkitnya ne-positivisme. Humanismenya ini dibangun berdasarkan narasi pembebasan manusia dari belenggu mitologi dan agama.
\end{abstract}

Kata Kunci: Teologi Islam, Rasionalis, Sutan Takdir Alisyahbana 


\section{Pendahuluan}

Indonesia merupakan salah satu negara yang menempati urutan teratas sebagai negara dengan populasi muslim terbesar di dunia. ${ }^{1}$ Indonesia juga memiliki berbagai bentuk demensi atau pluralitas, baik pluralitas budaya, sosial, seni, dan pemikiran. Semuanya itu merupakan salah satu bentuk identitas. Identitas pluralitas inilah yang membentuk negara kesatuan yang dikenal dengan kesatuan republik Indonesia. Negara Kesatuan Republik Indonesia ini telah dirintis oleh para pendiri bangsa dan telah mampu bertahan hingga kini. Jika bangsa yang besar ini memiliki kekayaan materi dan pemikiran yang cukup melimpah maka bangsa ini juga memiliki sistem filsafat tersendiri dan karya nenek moyangnya-pun bisa dijadikan sebagai paradigma berfikir. Dalam hal ini penulis akan fokus pada pokok pemikiran S. Takdir Alisyahbana.

Franz Magnis Soseno, dalam kegiatan semiloka " "merumuskan identitas filsafat Indonesia" yang diadakan oleh program pasca serjana fakultas filsafat UGM Yogyakarta pada 8 september 2009 telah memaparkan tema tentang "Melacak filusuf dan filsafat Indonesia" Magnis Suseno juga telah memberikan masukan dan penjelasan tentang pemikiran mengenai inventarisasi khazanah filsafat nusantara. Sutan Takdir Alisyahbana merupakan salah satu ahli sastra dan juga termasuk pemikir/ filosof Indonesia. Banyak karya (sastra) yang di tulis oleh STA, ia termasuk orang yang sangat peduli dengan kebudayaan Indonesia, sehingga ia dikenal dengan pejuang kebudayaan. STA membagi kebudayaan Indonesia ini menjadi empat lapis yaitu; kebudayaan Indonesia asli, kebudayaan India, kebudayaan Arab-Islam, dan kebudayaan modern Eropa-Amerika ${ }^{3}$. Untuk memahami kebudayaan Indonesia, menurutnya harus juga memahami empat kebudayaan ini yang dimana unsur dari kebudayaan ini bermacam-macam cara percampurannya dan harus bisa mendapatkan pengetahuan agar dapat bisa membandingkan budaya satu dengan budaya lainnya.

Dalam waktu dua puluh tahun terakhir semasa hidupnya, STA memfokuskan perhatiannya pada soal perbandingan kebudayaan dan soal perubahan kebudayaan dan pada waktu itu dia mendapat kunci untuk dapat memahamkan dan membandingkan

1 Dalam laporan view research, sebuah lembaga risearch Global pada tahun 2010. Lihat https://www.kabarmakassar.com/posts/view/6209/cek-fakta-jokowi-indonesia-negara-penduduk-islamterbesar-di-dunia.html, diaksies pada hari Ahad, 06 Oktober 2019 jam 23.00 WIB.

${ }^{2}$ Franz Magnis-Suseno, Pijar-pijar filsafat: dari Gatholoco ke filsafat perempuan, dari Adam Müller ke Postmodernisme (Yogyakarta: Penerbit Kanisius, 2005), h. 205.

${ }^{3}$ Sutan Takdir Alisjahbana, Perkembangan sejarah kebudayaan Indonesia dilihat dari jurusan nilai-nilai: ceramah pada tanggal 11 Februari 1975 di Gedung Kebangkitan Nasional, Jakarta (Jakarta: Idayu Press, 1977), h. 5. 
kebudayaan dalam pengertian nilai. ${ }^{4}$ Menurut STA dalam bukunya, (values as integrating forcec in personalty, society and culture yang ditulis di Kuala Lumpur, University of malaya press, 1996) mengatakan bahwa nilai itu mempunyai kedudukan yang istimewa, bukan saja sebagai unsur inti tiap-tiap kebudayaan yang membedakan antara manusia dengan hewan, tetapi juga membedakan kebudayaan yang satu dengan kebudayaan yang lain.

Berbagai penelitian yang ditulis oleh beberapa peneliti tentang tokoh ini (S. Takdir Alisyahbana) hanya melihat beberapa aspek saja, ada yang melihat sisi humanisnya, ada yang melihat sisi budayanya, ada juga melihat dari sisi sastranya. Namun dalam tulisan ini penulis ingin melihat aspek rasionalnya yang kemudian itu dijadikan sebagai budaya berfikir atau paradigma berfikir masyarakat Indonesia secara umum. Dengan demikian maka timbullah pertanyaan besar yaitu, bagaimana bentuk paradigma yang dibangun oleh Sutan Takdir Alisyahbana?

\section{Metode}

Jenis penelitian ini merupakan jenis penelitian pustaka (library research) dengan penyajian data kualitatif-interpretatif, dimana objek utamanya ialah dari buku-buku kepustakaan yang tersedia. Tentu saja buku-buku tersebut berkaitan dengan pokok pembahasan penelitian ini. Penelitian ini dilakukan dengan menggunakan prosedur: pengumpulan, analisis dan penyajian data. Dalam penelitian ini terdapat dua sumber data, yaitu data primer dan data sekunder. Data primer dalam penelitian ini diperoleh dari bukubuku yang ditulis langsung oleh Sutan Takdir Alisyahbana seperti: "Perkembangan Sejarah Kebudayaan Indonesia Dilihat dari Segi Nilai-Nilai”, “The Indonesian Language and Literature", "Pembimbing ke Filsafat", "Values as Integrating Vorces in Personality, Society and Culture”, “The Failure of Modern Linguistics". Sedangkan data sekundernya yaitu jurnal, artikel yang membahas tentang Sutan Takdir Alisyahbana.

\section{Hasil Penelitian dan Pembahasan}

Penelitian ini bermaksud untuk mengungkapkan kebudayaan Indonesia yang ingin dibentuk oleh Sutan Takdir Alisyahbana yaitu kebudayaan berfikir rasional. Dimana kita ketahui bahwa di Indonesia merupakan negara yang mayoritas penduduknya masyarakat

\footnotetext{
${ }^{4}$ Yuhasnil Yuhasnil, "Perubahan Nilai Nilai Budaya Dalam Proses Modernisasi Di Indonesia," Menara Ilmu 13, no. 5 (14 April 2019), https://doi.org/10.33559/mi.v13i5.1375, diaksies pada hari Rabu, 16 Oktober 2019 jam 23.33 WIB.
} 
muslim, sehingga kebudayaan Indonesia tidak jauh berbeda dengan kebudayaan Islam. Sebagaimana kita ketahui bahwa kebudayaan Islam merupakan kebudayaan yang lebih mengedepankan suasana hati dan ketenangan ruhani, sementara aspek rasionalitasnya di nomor duakan bahkan dihilangkan, kendatipun Rasulullāh SAW sudah mencontohkan kerasionalannya yaitu dengan sifat cerdasnya (Fathānah) nya, dan seharusnya ummat Rasulullāh SAW (Islam) memiliki kecerdasan yang melebihi umat lainya. Namun faktanya hari ini berbeda, seolah-olah aspek rasionalitas berdikotomi dengan suasana hati (aspek ruhani), padahal sejak awal dimasa Rasulullāh SAW tidak mendikotomikan antara keduanya.

Beberapa tulisan yang ditulis oleh peneliti tentang tokoh ini (S. Takdir Alisyahbana) hanya melihat beberapa aspek saja, ada yang melihat sisi humanisnya, ada yang melihat sisi budayanya, ada juga melihat dari sisi sastranya. Namun dalam tulisan ini, penulis ingin melihat aspek rasionalnya yang kemudian itu dijadikan sebagai budaya berfikir atau paradigma berfikir masyarakat Indonesia secara umum.

\section{Riwayat Hidup dan Sosial-Budaya Sutan Takdir Alisyahbana}

Sutan Takdir Alisyahbana (STA) seorang tokoh dalam bidang kebudayaan indonesia yang laihir pada tanggal 11 Februari 1908 di Natal, Tapanuli Selatan yang terletak di pantai barat Sumatera. Ia berasal dari daerah Minangkabau dan ia tidak lepas dari pengaruh keluarga. Ibunya berasal dari Natal, yang adat istiadat dan bahasanya adalah Minangkabau. Ayahnya juga berasal dari Natal yang berdarah jawa yang akhirnya merantau ke Tanahpadang, Bengkulu. Ayahnya pandai main bola, menjahit, memperbaiki arloji dan juga gemar berpolemik. Ayahnya yang bernama Almarhum Raden Alisyahbana gelar sutan Amin dan berprofesi sebagai guru di Bengkulu tersebut telah mempengaruhi pemikirannya. ${ }^{5}$

Sutan Takdir Alisyahbana (STA) masih ada hubungan dengan sutan Syahrir yang dulunya juga berasal dari Sumatera dan Mr. Muhammad syah yang dulunya menjadi rektor universitas cendana, Kupang. Sutan Syahrir juga sangat mempengaruhi pikirannya. Dari keluarga muslim yang taat beribadah, Sutan Takdir Alisyahbana (STA) dilahirkan dan sosoknya kemudian menjadi pribadi yang ulet, gigih dan suka bekerja keras.

Sikap hidup Sutan Takdir Alisyahbana (STA) ternyata bukan hanya di pengaruhi oleh keluarganya, tapi banyak dipengaruhi oleh teman-temannya. Sekitar tahun 1925, ia

${ }^{5}$ Sutan Takdir Alisjahbana, Pembangunan ekonomi \& [i. e. dan] etik ekonomi Islam: prasaran dalam konperensi Himpunan Falsafah Indonesia, Djakarta, 13-16 Djanuari 1972 (Jakarta, 1972), h. 52. 
mulai tertarik dengan pribadi Suekarno, ia mengingat perkataan Suekarno yang menyatakan bahwa "rakyat yang miskin dan lapar itu juga rakyat yang perutnya keroncongan”. Di Hogere Kweekschool, ia mulai membaca dan menulis dengan bahasa Belanda. ${ }^{6}$

Sutan Takdir Alisyahbana (STA) memulai karirnya menjadi guru di Palembang tahun 1928-1930. Kemudian Sutan Takdir Alisyahbana (STA) pindah ke Jakarta dan bekerja di Balai Pustaka sebagai hoofredacteur di majalah Panji Pustaka. ${ }^{7}$ Seminggu setalah ia menjadi guru, Sutan Takdir Alisyahbana (STA) sakit jantung dan dirawat di rumah sakit Cimahi Bandung setelah tiga minggu di rumah sakit dia mampu menyeleseikan karyanya Tak Putus Dirundung Malang di Bandung pada tahun 1982. Kemudian, ia mengirimkannya ke Balai Pustaka.

Ketika menulis roman tersebut, ada dorongan perasaan dan pikiran yang berdesakan dalam hatinya. Kondisi ini dapat ditemui, ketika Sutan Takdir Alisyahbana (STA) menulis roman yang berjudul Tak Putus Dirundung Malang tersebut untuk pertama kalinya. Tak lama kemudian, Sutan Takdir Alisyahbana (STA) menulis roman yang berjudul Dian Yang Tak Kunjung Padam, kemudian disusul lagi dengan judul Anak Perawan di Sarang Penjamun. Selanjutnya dalam Layar Terkembang, Sutan Takdir Alisyahbana (STA) mulai menyadari akan perubahan dalam masyarakat yang berlaku di dalam negerinya dan negeri lain. Kemudian, Sutan Takdir Alisyahbana (STA) menulis Grota Azzura dan Kalah Menang yang dinilai oleh pengamat sastra sebagai novel diskusi dan karya-karya tersebut menjadi kering disebabkan oleh rasionalismenya. ${ }^{8}$

Pada tahun 1929, Sutan Takdir Alisyahbana (STA) menikah dengan Raden Ajeng Rohani di Bengkulu. Tahun 1930, Sutan Takdir Alisyahbana (STA) pindah ke Jakarta dan anak pertamanya lahir kemudian diberi nama Samiati. Sutan Takdir Alisyahbana (STA) kemudian melanjutkan pelajarannya dan mengambil kursus malam di Hoofdate Cursus. Dan pada tahun 1935 istri tercintanya meninggal dunia, sehingga ia menulis sajak Tebaran Mega. ${ }^{9}$ Setelah istrinya meninggal dunia, kemudian pada tahun 1941 Sutan Takdir Alisyahbana (STA) menikah lagi dengan Raden Roro Sugiarti, tiga bulan sebelum

6 Sumasno Hadi, "Pemikiran Sutan Takdir Alisyahbana Tentang Nilai, Manusia, Dan Kebudayaan,"Jurnal Filsafat 21, no. 1 (22 September 2016): 1-19, https://doi.org/10.22146/jf.3118. diaksies pada hari Selasa, 15 Oktober 2019 jam 14.00 WIB.

${ }^{7}$ Mas'oed Abidin dan Pusat Pengkajian Islam dan Minangkabau, ed., Ensiklopedi Minangkabau, Ed. awal (Padang: Pusat Pengkajian Islam dan Minangkabau, 2005), h. 169.

${ }^{8}$ Herry Gendut Janarto, Matiur M. Panggabean, bunga pansur dari Balige: pengabdian dan keteguhan iman seorang istri prajurit (Jakarta: Gramedia Pustaka Utama, 2010), h. 59.

${ }^{9}$ Abidin dan Pusat Pengkajian Islam dan Minangkabau, Ensiklopedi Minangkabau, h. 174.

Tribakti: Jurnal Pemikiran Keislaman

Volume 31, Nomor 1, Januari 2020 
Jepang menyerah dan pada waktu yang sama Sutan Takdir Alisyahbana (STA) juga sedang menjadi mahasiswa Rechtschogeschool, kemudian pada tahun 1952 istri keduanya ini meninggal dunia. Pada tahun 1953 Sutan Takdir Alisyahbana (STA) kemudian menikah lagi dengan Dr. Margareth Axer yang ketika itu sedang menjabat sebagai direktur kebudayaan pada surat kabar koblenz.

Dengan demikian Sutan Takdir Alisyahbana (STA) menikah tiga kali yang juga telah mempengaruhi segala bentuk kegiatannya. Dua istrinya terdahulu bernama Raden Ajeng Rohani yang telah dinikahi pada tahun 1929 dan meninggal dunia pada tahun 1935 di Jakarta, dan Raden Roro Sugiarti yang telah dinikahi pada tahun 1941 dan meninggal dunia pada tahun 1952 di Los Angeles, dan terakhir ia menikah dengan Dr. Margareth Axer yang telah dinikahi pada tahun 1953 di Bonn, Jerman Barat. Dari ketiga istrinya ini, Sutan Takdir Alisyahbana (STA) mempunyai sembilan anak. ${ }^{10}$ Pada hari ahad tanggal 17 juli 1994, Sutan Takdir Alisyahbana (STA) meninggal dunia dan ia dikenang sebagai pejuang kebudayaan.

\section{Pokok Pemikiran Sutan Takdir Alisyahbana}

Sutan Takdir Alisyahbana selain dikenal sebagai sastrawan Indonesia bahkan ia disebut sebagai bapak bahasa Indonesia, dia juga dikenal sebagai pejuang kebudayan Indonesia. Pemikiran Sutan Takdir Alisyahbana (STA) dipilih berdasarkan pada perhatiannya terhadap perkembangan kebudayaan, khususnya kebudayaan Islam Indonesia. Hal ini bisa dilihat dari perjalanan yang pada awalnya dia berasal dari keluarga yang beragama Islam. Meskipun pada masa kecilnya, dia tidak dikategorikan mahir dalam mendalami agama, tetapi dalam perjalanannya setelah mempelajari kebudayaan barat, dia tertarik kepada kebudayaan Islam.

Pemikiran Sutan Takdir Alisyahbana (STA) berakar dalam paham humanis yang berkembang di Eropa sejak Renaissance hingga bangkitnya neo-positivisme. ${ }^{11}$ Humanismenya ini di bangun berdasarkan tiga narasi besar; pertama, pembebasan manusia dari belenggu mitologi dan agama, suatu pemikiran yang memuncak dengan perkembangan pemikiran rasionalismenya Rene Descartes dan emperisme John Locke, yang dipadu oleh Immanuel Kant dalam idealismenya. Kedua, bertujuan spirit yang dijumpai dalam idealisme Hegel dan kaum romantik, seperti Fichte dan Schelling. Ketiga,

\footnotetext{
${ }^{10}$ Janarto, Matiur M. Panggabean, bunga pansur dari Balige, h. 60.

${ }^{11}$ Abuhasan Asy’ari, ed., STA dalam kenangan, Cet. 1 (Jakarta: Dian Rakyat, 2008), h. 132. 
hermeneutika makna yang diajukan oleh penganjur paham historisme seperti Wilhem Dilthey. ${ }^{12}$ Semua itu melahirkan humanisme sekuler dan fundamentalisme rasional. Tiga narasi ini menggantikan narasi besar sebelumnya, ketika manusia terikat kepada mitologi agama.

Meskipun Sutan Takdir Alisyahbana (STA) mengadopsi tentang pemikiran barat, tetapi dia juga memperhatikan kebudayaan Islam di Indonesia. Mengenai kebudayaan Islam, Sutan Takdir Alisyahbana (STA) mengungkapkan bahwa sekitar abad ke-13 atau ke-14 M, bangsa Indonesia telah berkenalan dengan kebudayaan Islam atau kebudayaan arab Islam. Sutan Takdir Alisyahbana (STA) mengungkapkan bahwa kebudayaan Islam itu berpusat pada kepercayaan kepada tenaga yang gaib, yang dalam kebudayaan Islam dinamakan Allah. Hal ini berbeda dengan kebudayaan Indonesia asli dan berbeda dengan hirarki dewa-dewa dan immanentisme budaya India, dan dalam kepercayaan Islam, ada jarak antara alam, manusia, dan tuhan. ${ }^{13}$ Kebudayaan Islam khususnya Indonesia itu juga dikonfigurasikan dalam nilai-nilai yaitu; nilai agama, nilai seni, nilai kuasa, nilai solidaritas, nilai ekonomi, dan nilai teori. ${ }^{14}$ Dengan demikian, kebudayaan Islam itu juga terdapat nilai-nilai yang terkomfigurasi sebagai keseluruhan gagasan, dan karya manusia yang terjelma dalam benda-benda kebudayaan yang diperoleh melalui belajar berdasarkan agama Islam.

Dari keenam nilai tersebut, mempunyai posisi yang berbeda dan saling berkaitan satu dengan yang lain dalam sebuah konfigurasi nilai. Jika tujuan atau proses peniliaan untuk mengetahui alam sekitar, yaitu menentukan dengan objektif identitas benda-benda dan kejadian-kejadian, inilah tahap proses penilaian teori yang menghasilkan ke arah pengetahuan, dan inilah yang disebut dengan nilai teori. Jika tujuannya adalah memakai atau menggunakan benda-benda dan kejadian-kejadian, inilah tahap proses penilaian ekonomi yang berlaku kearah guna yang sebesar-besarnya untuk hidup dan kesenangan hidup, dan inilah yang disebut dengan nilai ekonomi/ kegunaan. Kombinasi antara nilai ekonomi dan nilai teori, dengan demikian inilah yang desebut oleh Suatan Takdir Alisyahbna (STA) dengan istilah aspek progresif. ${ }^{15}$

\footnotetext{
${ }^{12}$ Hadi, "Pemikiran Sutan Takdir Alisyahbana Tentang Nilai, Manusia, Dan Kebudayaan."

${ }^{13}$ M. Amin Syukur, Teologi Islam terapan: upaya antisipatif terhadap hedonisme kehidupan modern (Solo: Tiga Serangkai Pustaka Mandiri, 2003), h. 23-24.

${ }^{14}$ Clive J. Christie, Southeast Asia in the twentieth century: a reader (London ; New York: Tauris, 1998), 175-76.

${ }^{15}$ Alisjahbana, Perkembangan sejarah kebudayaan Indonesia dilihat dari jurusan nilai-nilai, h. 10 .
} 
Nilai agama adalah nilai kekudusan yang menghubungkan manusia dengan kegaiban alam semesta untuk mencari arti hidupnya. Nilai seni adalah nilai yang melihat segala sesuatu dari bentuk expresi yang menjelma dalam keindahan. Dari proses penilaian dan nilai-nilai itu menjadi dasar pembentukan benda-benda atau objek agama dan seni. ${ }^{16}$ Nilai agama lebih menekankan kekudusan dan kebenaran alam semesta, sedangkan nilai seni lebih menekankan keindahan estetik alam semesta dan keduanya sama-sama menekankan aspek intuisi dan perasaan maka kombinasi antara keduanya (nilai agama dan nilai seni) ini disebut dengan aspek ekspresif dari kebudayaan. ${ }^{17}$ Terakhir proses penilaian solidaritas, dalam proses penilain solidaritas ini yang dituju adalah kekuasaan, yaitu kita merasa puas jika orang lain mengikuti aturan-aturan atau norma yang kita buat, artinya bahwa kita mempunyai otoritas tinggi dan kuasa atas mereka. Sehingga pada tahap ini kita berada pada titik hubungan cinta, persahabatan, simpati dengan sesama manusia, yaitu kita menghargai mereka sebagai individu atau golongan dengan kemungkinankemungkinannya sendiri dan puas jika dapat membantu mereka dalam perkembangan mereka.

\section{Karya-Karya Sutan Takdir Alisyahbana (STA)}

Karya Sutan Takdir Alisyahbana (STA) dalam bidang kebudayaan sangat beragam, baik dalam bentuk novel, pelajaran tata bahasa, filsafat termasuk filsafat kebudayaan, beragam presentasi dalam berbagai seminar dan dialog kebudayaan di dalam dan luar negeri. STA adalah "fajar modernisme" Indonesia. ${ }^{18}$ Padanya-lah akan didapati semangat membangun Indonesia modern justru sebelum Indonesia lahir. Lewat pemikirannya di bidang sastra, bahasa, filsafat, dan kebudayaan yang tersebar dalam berbagai tulisan dan buku, STA tak lelah-lelahnya memperjuangkan kemajuan Indonesia. Sebagai tokoh besar sastra, bahasa, kebudayaan, intelektual dan filsafat, STA telah melahirkan banyak karya, di antaranya sebagai berikut;

Tak Putus Dirundung Malang (novel, 1929), Dian Tak Kunjung Padam (novel, 1932), Tebaran Mega (kumpulan sajak, 1935), Tatabahasa Baru Bahasa Indonesia (1936), Layar Terkembang (novel, 1936), Anak Perawan di Sarang Penyamun (novel, 1940), Puisi Lama (bunga rampai, 1941), Puisi Baru (bunga rampai, 1946), Pelangi (bunga rampai, 1946), Pembimbing ke Filsafat (1946), Dari Perjuangan dan Pertumbuhan Bahasa

\footnotetext{
${ }^{16}$ Riris K. Sarumpaet, ed., Sastra masuk sekolah, Cet. 1 (Magelang: IndonesiaTera, 2002), h. 35.

${ }^{17}$ Alisjahbana, Perkembangan sejarah kebudayaan Indonesia dilihat dari jurusan nilai-nilai, h. 10.

${ }^{18}$ Abdul Malik, Menjemput tuah, menjunjung marwah, Cetakan pertama (Depok, Indonesia: PT Komodo Books, 2012), h. 213. 
Indonesia (1957), The Indonesian Language and Literature (1962), Revolusi Masyarakat dan Kebudayaan di Indonesia (1966), Kebangkitan Puisi Baru Indonesia (kumpulan esai, 1969), Grotta Azzura (novel tiga jilid, 1970 \& 1971), Values as Integrating Vorces in Personality, Society and Culture (1974), The Failure of Modern Linguistics (1976), Perjuangan dan Tanggung Jawab dalam Kesusastraan (kumpulan esai, 1977), Dari Perjuangan dan Pertumbuhan Bahasa Indonesia dan Bahasa Malaysia sebagai Bahasa Modern (kumpulan esai, 1977), Perkembangan Sejarah Kebudayaan Indonesia Dilihat dari Segi Nilai-Nilai (1977), Lagu Pemacu Ombak (kumpulan sajak, 1978), Amir Hamzah Penyair Besar antara Dua Zaman dan Uraian Nyanyian Sunyi (1978), Kalah dan Menang (novel, 1978), Menuju Seni Lukis Lebih Berisi dan Bertanggung Jawab (1982), Kelakuan Manusia di Tengah-Tengah Alam Semesta (1982), Socio-cultural Creativity in the Converging and Restructuring Process of the Emerging World (1983), Kebangkitan: Suatu Drama Mitos tentang Bangkitnya Dunia Baru (drama bersajak, 1984), Perempuan di Persimpangan Zaman (kumpulan sajak, 1985), Seni dan Sastra di Tengah-tengah Pergolakan Masyarakat dan Kebudayaan (1985), Sajak-sajak dan Renungan (1987).

Selain itu, STA juga memiliki karya lain berupa buku dimana ia bertindak sebagai editor, dan beberapa buku terjemahan, diantaranya; Kreativitas (kumpulan esai, tahun 1984), Dasar-Dasar Kritis Semesta dan Tanggung Jawab Kita (kumpulan esai, tahun 1984), Nelayan di Laut Utara (karya Pierre Loti, terjemahan tahun 1944), Nikudan Korban Manusia (karya Tadayoshi Sakurai; terjemahan bersama Soebadio Sastrosatomo, 1944).

Pokok Pemikiran tentang Kebudayaan Barat (Eropa) dan Kebudayaan Timur (Islam) sebagai Teologi dan Rasionalitas Sutan Takdir Alisyahbana

Sebelum mengetahui pandangan Sutan Takdir Alisyahbana (STA) tentang kebudayaan barat dan timur, perlu untuk meninjau tentang istilah timur dan barat. Menurut Sachari, wilayah Asia termasuk Indonesia itu sering di kategorikan sebagai negara timur. Sedangkan wilayah Eropa itu sering dikategorikan sabagai negara barat. Sehingga akibat dari pengertian tersebut terjadi pemisahan semu, dengan demikian muncul kebudayaan barat diidentikkan dengan rasionalitas dan kebudayaan timur diidentikkan dengan suasana hati. ${ }^{19}$ Dalam peradaban dunia, kebudayaan timur dan barat itu diidentikkan dengan perselisihan, perseteruan, dan permusuhan, dari pada saling

19 A. Budi Susanto, ed., Penyam(b)ung suara lidah rakyat (Yogyakarta: Penerbit Kanisius : Lembaga Studi Realino, 2008), h. 9. 
mengerti, persahabatan dan bekerja sama. Menurut orang timur, barat selalu dihubungkan dengan kapitalisme, tehnologi dan imperealisme. Bagi masyarakat barat, timur selalu berkonotasi dengan negara-negara yang padat penduduknya, miskin, terbelakang, dan tradisional.

Menurut Schari, timur lebih menekankan aspek intuisi dari daripada aspek akal. Pada masyarakat timur, pusat kepribadian orang itu terletak pada hati, yang mempersatukan akal budi, intuisi, kecerdasan dan perasaan. ${ }^{20}$ Masyarakat timur menghayati hidup apa adanya, dan bukan semata akal. Hati atau rasa sebagai pengganti logika kaku yang serba terbatas dalam menghadapi kebenaran hidup. ${ }^{21}$ Berdasarkan pemaparan diatas, kebudayan barat adalah kebudayan Eropa-Amerika yang menekankan pada rasionalitas, sedangkan kebudayaan timur adalah kebudayaan Asia yang lebih menekankan pada intuisi dan perasaan hati.

Untuk mengetahui pandangan Sutan Takdir Alisyahbana (STA) tentang kebudayaan barat dan timur, perlu kita melihat polemik dalam kebudayaan. Meurut Sutan Takdir Alisyahbana (STA), kebudyaan itu bertolak belakanag dari pengamatan terhadap lingkungan sekitarnya. Pemikiran kebudayaan yang muncul dikalangan cendekiawan Indonesia pada tahun 1930-an menyebabkan Sutan Takdir Alisyahbana (STA) tampil dengan semboyan tegas yang merupakan langkah awal dari suatu polemik kebudayaan. ${ }^{22}$

Dalam polemik kebudayaan, Sutan Takdir Alisyahbana (STA) berpendirian bahwa konsep kebudayaan nasional Indonesia yang dalam karangannya disebut "Kebudayaan Indonesia Raya" itu, sebenarnya baru mulai timbul dan disadari oleh generasi muda Indonesia pada permulaan abad ke-20 yang berjiwa dan bersemangat ke Indonesiaan. Saat itu yang ada hanya kebudayaan-kebudayaan suku bangsa di daerah. Sutan Takdir Alisyahbana (STA) kemudian menganjurkan agar generasi tidak terlampau tersangkut dalam kebudayaan-kebudayaan pra-Indonesia dan dapat membebaskan diri dari kebudayaan kesukubangsaannya, tetapi berkobar-kobar dengan semangat Indonesia

\footnotetext{
${ }^{20}$ Agus Sachari, Estetika (Bandung: Penerbit ITB, 2002), h. 6.

21 Rendo bangku Koto Gadang (Guguk Malintang, Padangpanjang Timur, Padangpanjang, Sumatera Barat: ISI Padangpanjang, 2016), h. 55.

${ }^{22}$ Polemik kebudayaan sekitar tahun 30-an itu melibatkan beberapa pemikir saat itu. Sanusi Pane menyarankan bahwa bangsa indonesia harus tetap berpaku pada kebudayaan Indonesia di tengah lajunya modernisasi. Hal ini merupakan bantahannya terhadap Sutan Takdir Alisyahbana (STA) yang menginginkan bahwa barat-lah sebagai barometer dalam perkembangan indonesia untuk maju kedepan untuk perkembangan globalisasi. Disini terdapat polemik ide atau gagasan pemikir indonesia khususnya islam dimana satu sisi berpenpendapat bahwa baratlah sebagai barometer kedepan disisi lain tetap mempertahankan indonesia. Dari fenomenan ini perlu untuk mencari tau bagaimana mengkaji pemikarn Sutan Takdir Alisyahbana.
} 
baru. ${ }^{23}$ Sutan Takdir Alisyahbana (STA). Secara umum membagi dua kebudayaan; kebudayaan Eropa (Barat) dan kebudayaan Asia (Timur).

\section{Kebudayaan Eropa (Barat)}

Hubungan dengan semangat atau jiwa nasional Indonesia, kebudayaan nasional Indonesia merupakan suatu kebudayaan yang di kreasikan dengan suatu yang baru, dengan mengambil banyak unsur dari kebudayaan barat.

Menurut Sutan Takdir Alisyahbana (STA), unsur-unsur kebudayaan barat yang penting untuk mengkreasikan kebudayaan Indonesia baru adalah teknologi, orientasi ekonomi, keterampilan berorganisasi secara luas, dan ilmu pengetahuan. Dalam membangun usaha, membangun Indonesia raya, orang Indonesia raya hendaknya mempertajam rasio akalnya dan mengambil alih dinamisme dunia barat. ${ }^{24}$

Menurut Sutan Takdir Alisyahbana (STA), konsep kebudayaan Indonesia di masa depan adalah kebudayaan modern. ${ }^{25}$ Kebudayaan Indonesia modern ini bukanlah kebudayaan robot. Kebudayaan ini bukanlah kebudayaan yang memerlukan otak encer semata, melainkan juga pribadi yang mampu melahirkan berfikir kritis dan mampu mengembangkan seluruh potensi dalam dirinya secara optimal. Sehingga, pribadi yang mandiri dan bertanggung jawab dalam kehidupan masyarakat itu akan terwujud dizaman modern ini. Dengan demikian, pemikiran kebudayaan Sutan Takdir Alisyahbana (STA) mengacu pada kebudayaan modern yang dibawa oleh ilmu, tehnologi, industri, dan rasionalitas ekonomi. Hal ini tidak berlebihan, mengingat latar belakangnya yang selalu mangagumkan dan selalu mempelajari cara berfikir barat.

Yang menarik perhatian Sutan Takdir Alisyahbana (STA) terhadap kebudayaan adalah bangkitnya kembali kebudayaan Eropa pada akhir abad pertengahan atau pada zaman renaissance. Ignas Kleden menyebut Sutan Takdir Alisyahbana (STA) sebagai seorang yang hidup dengan cita-cita dan keyakinan renaissance. ${ }^{26}$ Sejarah Indonesia yang latar belakang sejarahnya itu sama sekali berbeda dengan Eropa. Hal ini menjadi sulit untuk menerapkan rennaissance secara

${ }^{23}$ Syukur, Teologi Islam terapan, h. 108.

${ }^{24}$ Alisjahbana, Pembangunan ekonomi \& [i. e. dan] etik ekonomi Islam, h. 32.

25 Alisjahbana, Perkembangan sejarah kebudayaan Indonesia dilihat dari jurusan nilai-nilai, h. 23.

${ }^{26}$ S. Takdir Alisjahbana, Manusia renaisans Indonesia: Prof. Dr. Mr. Sutan Takdir Alisjahbana: simposium internasional para pakar tentang relevansi kekinian dan kemasadepanan pembaharuan pemikiran dan gagasan budaya, bahasa, filsafat, sastra keindonesiaan Prof. Dr. Mr. Sutan Takdir Alisjahbana, Cet. 1 (Jakarta: Dian Rakyat, 2008), h. 232. 
murni. Untuk itu Sutan Takdir Alisyahbana (STA) menafsirkan kebangkitan kebudayaan itu sebagai pembebasan dari kebudayaan lama untuk bangkitnya kebudayaan baru.

Kemudian Sutan Takdir Alisyahbana (STA) membagi kebudayaan menjadi dua bagian, yaitu: sejaraha pra-Indonesia dan sejarah Indonesia. ${ }^{27}$ Sejarah Indonesia dimulai pada abad XX, ketika suatu 'generasi baru' itu lahir, dengan kesadarannya hendak menempuh suatu jalan yang baru bagi bangsa dan negaranya. Zaman sebelumnya disebut zaman jahiliyah Indonesia, yang hanya mengenal sejarah Sri Wijaya dan sebagainya. Sehingga bangkitnya kebudayaan baru Indonesia bukanlah renaissance melainkan mengambil sesuatu relatif baru yang sama sekali dari kebudayaan barat yang lahir dari rahim renaissance.

Dengan demikian, kebudayaan barat yang lahir dari rahim renaissance itu adalah berkebudayaan moderan yang di bawa oleh ilmu, teknologi, industri dan rasionalitas ekonomi.

\section{Kebudayaan Asia (Timur)}

Adapun pendapat Sutan Takdir Alisyahbana (STA) tentang kebudayaan timur, perlu dilihat dari perjalanan hidupnya dalam mempelajari agama Islam. Pada waktu kecilnya, Sutan Takdir Alisyahbana (STA) tidak menggunakan kesempatan secara sungguh-sungguh untuk mempelajari agama. ${ }^{28}$ Sutan Takdir Alisyahbana (STA) tidak pernah menamatkan Al-Qur'an pada masa hidupnya. Sutan Takdir Alisyahbana (STA) lebih tertarik mempelajari kebudayaan barat. ${ }^{29}$ Setelah Sutan Takdir Alisyahbana (STA) mempelajari kebudayaan barat, maka setelah itu pula dia mempelajari agama. Agama menurutnya dibatasi oleh kepercayaan. Agama itu menjadi dasar percaya yaitu kepada apa yang dikatakan oleh kitab sucinya. ${ }^{30}$

Sutan Takdir Alisyahbana (STA) tertarik terhadap Islam itu berawal ketika beliau mendapatkan kesempatan membaca dan belajar tentang kemajuan kebudayaan barat. Sutan Takdir Alisyahbana (STA) mendapatkan buku-buku yang dijual oleh

\footnotetext{
${ }^{27}$ Acep Zamzam Noor, 33 tokoh sastra Indonesia paling berpengaruh, Cetakan pertama (Jakarta: KPG (Kepustakaan Populer Gramedia), 2014), h. 432.

${ }^{28}$ Yuda B. Tangkilisan, M. Iskandar, dan Indonesia, ed., Penulisan sejarah: pemikir kebudayaan, Cet. 1 (Jakarta: Direktorat Nilai Sejarah, Direktorat Jenderal Sejarah dan Purbakala, Kementerian Kebudayaan dan Pariwisata, 2010), h. 179.

${ }^{29}$ S. Takdir Alisjahbana, Pemikiran Islam dalam menghadapi globalisasi dan masa depan umat manusia: kumpulan esai, Cet. 1 (Jakarta: Dian Rakyat, 1992), h. 5.

${ }^{30}$ Fauzan Saleh, Modern trends in Islamic theological discourse in 20th century Indonesia: a critical study, Social, economic, and political studies of the Middle East and Asia, v. 79 (Leiden ; Boston: Brill, 2001), h. 152. 
orang-orang Belanda, ketika ia ditahan oleh Jepang. Kemudian, hal ini menjadi akar pemikiran Sutan Takdir Alisyahbana (STA) dimana kebudayaan barat adalah kebudayaan modern yang merata keseluruh dunia. Kemudian Sutan Takdir Alisyahbana (STA) bertemu dengan pemikir-pemikir muslim. ${ }^{31}$ Kemudian Sutan Takdir Alisyahbana (STA) meneliti suasana kemerosotan umat Islam. Dalam menggambarkan sebuah kemerosotan ini, Sutan Takdir Alisyahbana (STA) melihat kecenderungan hukum dan suasana sebuah desa di pinggiran Jakarta yang memakai kaca mata normatif. ${ }^{32}$ Menurut Sutan Takdir Alisyahbana (STA), keterbelakangan umat Islam dipandang sebagai ketidak mampuan untuk mereguk etos Islam yang dinamis dan kreatif.

Menurut Sutan Takdir Alisyahbana (STA), dunia Islam dan masyarakat Islam terus menerus mengalami kemunduran selama beberapa abad ini, orang Islam menunjukkan perubahan di dalam mental umat Islam. Abad ke-8 sampai abad ke-12, umat Islam itu sangat dinamis, menguasai ilmu pengetahuan, teknologi dan menguasai dunia. ${ }^{33}$ Ketika renaissance, semangat kekhalifahan manusia yang bertanggung jawab atas hidupnya sendiri sebagai wakil Tuhan tersebut berpindah ke tangan orang-orang Eropa. Saat itu, orang Eropa telah dapat menguasai dunia dan umat Islam dan mengarahkan pikirannya ke arah akherat saja.

Di Indonesia, umat Islam menjadi ragu-ragu dan enggan untuk maju. Sutan Takdir Alisyahbana (STA), menyarankan umat Islam Indonesia untuk maju, memperbaiki, mengasah otaknya, dan merebut dunia ilmu pengetahuan. ${ }^{34}$ Kelemahan Islam dan kebudayaannya menurut Sutan Takdir Alisyahbana (STA), bukan hanya dalam bidang ilmu, tetapi juga dalam bidang ekonomi. Daya tarik Sutan Takdir Alisyahbana (STA) terhadap Islam adalah kedudukan akal (rasio) dalam kemajuan ilmu, teknologi dan ekonomi. Hal ini ditambah dengan bertemunya Islam dengan perkembangan kebudayaan barat atau kebudayaan modern.

Sutan Takdir Alisyahbana (STA) mempelajari agama Islam bersama-sama dengan mempelajari kebudayaan yang luas dalam lingkungan Indonesia dan dalam

${ }^{31}$ S. Takdir Alisjahbana, Pemikiran Islam dalam menghadapi globalisasi dan masa depan umat manusia: kumpulan esai, Cet. 1 (Jakarta: Dian Rakyat, 1992), h. 9.

32 Choirotun Chisaan, Lesbumi: strategi politik kebudayaan, Cet. 1 (Yogyakarta: LKiS : Distribusi, LKiS Pelangi Aksara Yogyakarta, 2008), h. 153.

${ }^{33}$ Michael Francis Laffan, Indi Aunullah, dan Rini Nurul Badariah, Sejarah Islam di Nusantara (Yogyakarta, 2015), h. 213.

${ }^{34}$ Nurcholish Madjid dan Muhamad Wahyuni Nafis, Islam agama kemanusiaan: membangun tradisi dan visi baru Islam Indonesia (Jakarta: Dian Rakyat, 2010), h. 58-60.

Tribakti: Jurnal Pemikiran Keislaman

Volume 31, Nomor 1, Januari 2020 
hubungan sejarah dunia. Kemudian Sutan Takdir Alisyahbana (STA) berkeyakinan bahwa keterbelakangan Islam sejak zaman renaissance adalah disebabkan oleh kesalahan penafsiran tentang agama dan kebudayaan Islam itu sendiri. ${ }^{35}$ Islam mempunyai syarat-syarat untuk kemajuan ilmu, ekonomi dan teknologi dunia modern. Tetapi interpretasi Islam itu sendiri yang menyebabkan pemeluk agama Islam dalam zaman modern ini mempunyai kedudukan yang rendah dalam kemajuan dunia.

Menurut Sutan Takdir Alisyahbana (STA), bangsa Indonesia ini harus memiliki sifat-sifat yang menggerakkan kemajuan dunia barat yaitu; materealisme, egoisme dan individualisme. ${ }^{36}$ Menurut Sutan Takdir Alisyahbana (STA), timur hanya dihadapkan dengan barat, jika mereka dapat merebut alat atau perkakas yang membuat barat kuat dan berkuasa. Meskipun Sutan Takdir Alisyahbana (STA) mengakui adanya persamaan antara jiwa barat dengan jiwa timur (Islam) yang asli, tetapi dia berpendirian untuk mengambil dasar-dasar dari barat.

Dalam pandangan Sutan Takdir Alisyahbana (STA), ${ }^{37}$ ada lima sakaguru tafsiran Islam untuk dunia modern yang akan dapat menguasai kebudayaan modern di Indonesia maupun diseluruh dunia dan memberi kebahagiaan, keselamatan bagi umat manusia. Kelima sakaguru tersebut ialah; dasar tauhid kepada Tuhan yang maha esa, dasar solidaritas sesama agama, dasar hakikat manusia sebagai khalifah, ilmu pengetahuan, dan dasar perkembangan ekonomi.

Pertama adalah dasar tauhid kepada Tuhan yang maha esa. Dasar tauhid ini adalah modal utama dalam berperilaku. Ketika seseorang tertimpa dalam suatu musibah, maka seseorang tetap ingat kepada keesaan Tuhan, tetap menjalankan perintah Tuhan, seperti melakukan sembahyang dan sebagainya. Ia juga mengungkapkan bahwa etik itu menentukan kelakuan manusia. Itu adalah intisari dan pokok tiap-tiap kebudayaan. ${ }^{38}$ Contoh adalah kejujuran. Ia juga termasuk orang yang jujur dalam menyampaikan ide gagasannnya baik tentang politik, nasionalisme, demokrasi, agama, pergerakan nasional dan sebaginya. Sikap tauhid ini merupakan modal dasar untuk mengurangi kehidupan dengan sesama manusia.

\footnotetext{
${ }^{35}$ Aden Wijdan S. Z, ed., Pemikiran \& peradaban Islam, Cet. 1 (Yogyakarta: Pusat Studi Islam, Universitas Islam Indonesia : Safiria Insania Press, 2007), h. 58-59.

${ }^{36}$ Yudiono K. S, Pengkajian kritik sastra Indonesia (Jakarta: Gramedia Widiasarana Indonesia, 2009), h. 194.

${ }^{37}$ Sutan Takdir Alisjahbana dan Ignas Kleden, Kebudayaan sebagai perjuangan: perkenalan dengan pemikiran S. Takdir Alisjahbana (Jakarta: Dian Rakyat, 1988), h. 142.

${ }^{38}$ Magnis-Suseno, Pijar-pijar filsafat, h. 179.
} 
Kedua adalah dasar solidaritas sesama manusia. Sutan Takdir Alisyahbana (STA) mempunyai sikap belas-kasih terhadap sesama dan memiliki hati ( $f u^{\prime} a d$ ) yang mulia. Pada masa sekarang ini perlu adanya rasa solidaritas terhadap manusia dan juga agama, dimana semua umat manusia di bumi yang satu menghadapi Tuhan yang satu. Meskipun demikian, kesolideran kadang diancam oleh perpecahan umat manusia yang menimbulkan perlombaan persenjataan dan oleh kecakapan umat manusia membuat bom nuklir yang dapat menghancurkan bumi kita. Sutan Takdir Alisyahbana (STA), mendirikan yayasan memajukan ilmu dan kebudayaan dengan tujuan agar pemuda tidak ke tangan NICA. ${ }^{39}$ Sutan Takdir Alisyahbana (STA) dan kawan-kawannya juga mengorganisir kursus-kursus tentang sosiologi, politik, dan lain-lainnya. Ia sendiri mendirikan kursus filsafat. ${ }^{40}$ kemudian usaha inilah yang menurut pemakalah suatu bentuk solidaritas terhadap pemuda saat itu. Berdasarkan pejelasan di atas, sikap solidaritas Sutan Takdir Alisyahbana (STA) tersebut bukan hanya dalam dataran teoritis saja, melainkan juga dalam dataran praktis. Sikap solidaritas tersebut dapat juga dikatakan sebagai sikap ke-khalifahan dimuka bumi ini.

Ketiga dasar hakikat manusia sebagai khalifah. Dasar hakikat manusia sebagai khalifah adalah wakil Tuhan di dunia, sebagai mahluk yang tertinggi diantara segala mahluk Tuhan. Dengan kekhalifahannya itu jelas bahwa manusia memegang tanggung jawab sebesar-besarnya atas diri dan segala bentuk mahluk di bumi yang sekalian terlingkup dalam konsep dan kehidupan kebudayaannya. Ketika hakikat manusia sebagai khalifah tersebut dihubungkan dengan Sutan Takdir Alisyahbana (STA), ia mempunyai tanggung jawab untuk memajukan rakyat. Dia merasa bangga terhadap rakyat Indonesia, akademisi, cendekiawan, yang sadar akan berjuang untuk bangsanya dan menjadi pedoman untuk anak muda. Ada beberapa usaha yang dilakukan oleh Sutan Takdir Alisyahbana (STA) diantaranya, dia memperjuangkan rakyat khususnya di sumatera, ia mendirikan jong sumatra. Dalam kesempatan tersebut, ia memajukan kesustraan dan mencoba mengkritik kesustraan lama, syair dan pantun. Ia juga bekerja keras untuk kemajuan bangsa Indonesia dan mencoba membuat istilah berbahasa Indonesia. Ia juga menulis suatu rancangan perjuangan

${ }^{39}$ Gama Media (Firm), ed., Etos kita: moralitas kaum intelektual, Cet. 1 (Yogyakarta: Gama Media bekerja sama dengan Teknokra, 2002), h. 54.

${ }^{40}$ Fridiyanto, Kaum intelektual dalam catatan kaki kekuasaan (Lampung: Gre Publishing, 2018), h. $168-174$. 
yang bersifat intelektual dan kebudayaan dalam suasana pendudukan Jepang yang menyebabkan ia masuk penjara. Meskipun ia masuk penjara, namun ia juga mencoba mendidik sesama tahanan untuk sadar, dan kemudian dapat membekali mereka setelah keluar dari penjara. Sebagai khalifah, Sutan Takdir Alisyahbana (STA) mencoba mengeluarkan ide-idenya untuk memajukan Indonesia di tengah kemajuan ilmu pengetahuan.

Keempat adalah ilmu pengetahuan. Berdasarkan ketauhidan kepada Tuhan, solidaritas sesama manusia, sebagai khalifah tersebut terletak pada dasar ilmu pengetahuan yang harus dikembangkan sehingga manusia sebagai khalifah Tuhan dapat menjalankan tanggung jawab seluas-luasnya atas bumi dan sesama mahlukNya. Ilmu akan terus berkembang sejalan dengan usaha manusia memperkembangkan budinya dan kebudyaannya. ${ }^{41}$ Dihubungkan dengan pribadi Sutan Takdir Alisyahbana (STA), ia banyak mengarang buku, membaca dan mengembangkan upaya untuk mengejar ilmu pengetahuan.

Mengenai ilmu pengetahuan, Sutan Takdir Alisyahbana (STA) menyarankan untuk menggunakan tehnik modern dan tidak memperdulikan ketika masyarakat masih menjalankan tradisi. ${ }^{42}$ Meskipun Sutan Takdir Alisyahbana (STA), berada dalam penjara, ia tetap belajar. Sutan Takdir Alisyahbana (STA) juga belajar filsafat Kant. Pikiran liberalnya sama dengan Syahrir. Untuk mengembangkan ilmu pengetahuan yang dimilikinya, ia mendirikan balai seni Toyabungkah. Balai tersebut sebagai sarana untuk bermain tari, sebagai pusat perenungan, penciptaan tari dan sebagai tempat belajar menari. Kemudian Sutan Takdir Alisyahbana (STA) dan teman-temannya mendirikan Internasional Associatins For Art and Future, dan ia juga menerbitkan Newsletter Art and Future, dan dari balai seni Toyabungkah ke seluruh dunia. Sutan Takdir Alisyahbana (STA) mengemukakan juga tentang menciptakan bahasa, dan memikirkan bahasa terbesar dunia yaitu bahasa Inggris. ${ }^{43}$

Dengan bahasa Inggris tersebut, orang Indonesia bisa mendapatkan informasi dan ilmu pengetahuan dari beberapa literatur berbahasa Inggris. Berdasarkan hal

\footnotetext{
${ }^{41}$ Mujīburrah mān, Feeling Threatened: Muslim-Christian Relations in Indonesia's New Order, ISIM Dissertations (Amsterdam: Amsterdam Univ. Press [u.a.], 2006), h. 342.

42 A. J. Sondakh, Richard A. D. Siwu, dan Reiner Emyot Ointoe, Si tou timou tumou tou =: Manusia hidup untuk memanusiakan manusia: refleksi atas evolusi nilai-nilai manusia, Cet. 2 (Jakarta: Pustaka Sinar Harapan, 2003), h. 55.

${ }^{43}$ Muridan S. Widjojo dan Mashudi Noorsalim, ed., Bahasa negara versus bahasa gerakan mahasiswa: kajian semiotik atas teks-teks pidato Presiden Soeharto dan selebaran gerakan mahasiswa, Cetakan pertama (Jakarta: LIPI Press, 2004), 127. 
tersebut, Sutan Takdir Alisyahbana (STA) mempunyai perhatian terhadap Ilmu pengetahuan. Ilmu pengetahuan tersebut harus dimiliki oleh orang Indonesia di tengah-tengah persaingan dunia yang tidak bisa terlepas dari aspek ekonomi.

Kelima adalah dasar perkembangan ekonomi. Disamping tauhid, solidaritas, hakikat sebagai khalifah dan ilmu pengetahuan, ekonomi juga sangat penting diperhatikan dalam mendukung ketentraman. Ekonomi memang sangat mendukung terciptanya ketentraman, dimana mereka mempunyai harta yang lebih untuk mengamalkan atau untuk menjalani ilmu agamanya, seperti naik haji, membiayai anak untuk sekolah, menyantuni anak yatim dan sebagainya. Menurut Sutan Takdir Alisyahbana (STA), umat Islam jika dilihat dari jalur ekonominya dengan pengetahuan akan hukum-hukum alam sebagai khalifah Tuhan di dunia ini tidak pantas hidup dalam kemiskinan. Karena dalam Islam terdapat tuntunan zakat dan fitrah yang harus di tunaikan untuk fakir dan miskin adalah suatu anjuran di tentukan oleh agama yang amat tepat dan berasio dalam zaman Nabi Muhammad. Hal ini bisa ditelusuri, ketika jumlah fakir miskin dan yatim piatu banyak, ketika hak-hak manusia masih belum bisa dikembangkan, ketika belum dapat dipungut pajak secara efisien dan adil seperti zaman modern sekarang. ${ }^{44}$ Dengan pernyataan tersebut, maka Sutan Takdir Alisyahbana (STA) mempunyai perhatian terhadap ekonomi.

Perhatian Sutan Takdir Alisyahbana (STA) terhadap sektor ekonomi juga bisa terlihat dari keterlibatannya ketika ia menjadi wakil konstituante dan sebagai wakil dari sumatera selatan untuk meminta otonomi daerah. Adapun alasannya adalah agar kekayaan itu bisa dinikmati oleh daerah dan tidak hanya dihabiskan di Jakarta dan Jawa pada waktu itu. ${ }^{45}$ Berdasarkan hal tersebut, Sutan Takdir Alisyahbana (STA) mengungkapkan tentang perlunya ekonomi untuk mendukung perkembangan ilmu pengetahuan dengan sikap tauhid solidaritas dan hakekat manusia sebagai khalifah dalam mengarungi kehidupan dunia ini.

\section{Kesimpulan}

Pemikiran Sutan Takdir Alisyahbana (STA) berakar dalam paham humanis yang berkembang di Eropa sejak Renaissance hingga bangkitnya ne-positivisme. Humanismenya ini dibangun berdasarkan tiga narasi besar; pertama, pembebasan

\footnotetext{
${ }^{44}$ Nurcholish Majid, Islam, kemodernan, dan keindonesiaan, Cet. 1 (Ujungberung, Bandung: Mizan : Didistribusikan oleh Mizan Media Utama, 2008), h. 237.

${ }^{45}$ Fridiyanto, Kaum intelektual dalam catatan kaki kekuasaan, h. 257.
} 
manusia dari belenggu mitologi dan agama, suatu pemikiran yang memuncak dengan perkembangan pemikiran rasionalismenya Rene Descartes dan emperisme John Locke, yang dipadu oleh Immanuel Kant dalam idealismenya. Kedua, kebertujuan spirit yang dijumpai dalam idealisme Hegel dan kaum romantik, seperti Fichte dan Schelling. Ketiga, hermeneutika makna yang diajukan oleh penganjur paham historisme seperti Wilhem Dilthey.

Secara umum membagi dua kebudayaan; kebudayaan Eropa (Barat) dan kebudayaan Asia (Timur). Menurut Sutan Takdir Alisyahbana (STA), unsur-unsur kebudayaan barat yang penting untuk mengkreasikan kebudayaan Indonesia baru adalah teknologi, orientasi ekonomi, keterampilan berorganisasi secara luas, dan ilmu pengetahuan. Dalam kebudayaan Asia (Islam) ada lima sakaguru sebagai tafsiran Islam untuk dunia modern yang akan dapat menguasai kebudayaan modern di Indonesia maupun diseluruh dunia dan memberi kebahagiaan, keselamatan bagi umat manusia. Kelima sakaguru tersebut ialah; dasar tauhid kepada Tuhan yang maha esa, dasar solidaritas sesama agama, dasar hakikat manusia sebagai khalifah, ilmu pengetahuan, dan dasar perkembangan ekonomi.

\section{Daftar Pustaka}

Abidin, Mas'oed, dan Pusat Pengkajian Islam dan Minangkabau, ed. Ensiklopedi Minangkabau. Ed. awal. Padang: Pusat Pengkajian Islam dan Minangkabau, 2005.

Aden Wijdan S. Z, ed. Pemikiran \& peradaban Islam. Cet. 1. Yogyakarta: Pusat Studi Islam, Universitas Islam Indonesia : Safiria Insania Press, 2007.

Alisjahbana, S. Takdir. Manusia renaisans Indonesia: Prof. Dr. Mr. Sutan Takdir Alisjahbana: simposium internasional para pakar tentang relevansi kekinian dan kemasadepanan pembaharuan pemikiran dan gagasan budaya, bahasa, filsafat, sastra keindonesiaan Prof. Dr. Mr. Sutan Takdir Alisjahbana. Cet. 1. Jakarta: Dian Rakyat, 2008.

- Pemikiran Islam dalam menghadapi globalisasi dan masa depan umat manusia: kumpulan esai. Cet. 1. Jakarta: Dian Rakyat, 1992.

- Pemikiran Islam dalam menghadapi globalisasi dan masa depan umat manusia: kumpulan esai. Cet. 1. Jakarta: Dian Rakyat, 1992.

Alisjahbana, Sutan Takdir. Pembangunan ekonomi \& [i. e. dan] etik ekonomi Islam: prasaran dalam konperensi Himpunan Falsafah Indonesia, Djakarta, 13-16 Djanuari 1972. Jakarta, 1972. 
- Perkembangan sejarah kebudayaan Indonesia dilihat dari jurusan nilai-nilai: ceramah pada tanggal 11 Februari 1975 di Gedung Kebangkitan Nasional, Jakarta. Jakarta: Idayu Press, 1977.

Alisjahbana, Sutan Takdir, dan Ignas Kleden. Kebudayaan sebagai perjuangan: perkenalan dengan pemikiran S. Takdir Alisjahbana. Jakarta: Dian Rakyat, 1988.

Asy’ari, Abuhasan, ed. STA dalam kenangan. Cet. 1. Jakarta: Dian Rakyat, 2008.

Chisaan, Choirotun. Lesbumi: strategi politik kebudayaan. Cet. 1. Yogyakarta: LKiS : Distribusi, LKiS Pelangi Aksara Yogyakarta, 2008.

Christie, Clive J. Southeast Asia in the twentieth century: a reader. London ; New York: Tauris, 1998.

Fridiyanto. Kaum intelektual dalam catatan kaki kekuasaan. Lampung: Gre Publishing, 2018.

Gama Media (Firm), ed. Etos kita: moralitas kaum intelektual. Cet. 1. Yogyakarta: Gama Media bekerja sama dengan Teknokra, 2002.

Hadi, Sumasno. "Pemikiran Sutan Takdir Alisyahbana Tentang Nilai, Manusia, Dan Kebudayaan." Jurnal Filsafat 21, no. 1 (22 September 2016): 1-19. https://doi.org/10.22146/jf.3118.

Janarto, Herry Gendut. Matiur M. Panggabean, bunga pansur dari Balige: pengabdian dan keteguhan iman seorang istri prajurit. Jakarta: Gramedia Pustaka Utama, 2010.

Laffan, Michael Francis, Indi Aunullah, dan Rini Nurul Badariah. Sejarah Islam di Nusantara. Yogyakarta, 2015.

Magnis-Suseno, Franz. Pijar-pijar filsafat: dari Gatholoco ke filsafat perempuan, dari Adam Müller ke Postmodernisme. Yogyakarta: Penerbit Kanisius, 2005.

Malik, Abdul. Menjemput tuah, menjunjung marwah. Cetakan pertama. Depok, Indonesia: PT Komodo Books, 2012.

Muj̄̄burraḥmān. Feeling Threatened: Muslim-Christian Relations in Indonesia's New Order. ISIM Dissertations. Amsterdam: Amsterdam Univ. Press [u.a.], 2006.

Noor, Acep Zamzam. 33 tokoh sastra Indonesia paling berpengaruh. Cetakan pertama. Jakarta: KPG (Kepustakaan Populer Gramedia), 2014.

Nurcholish Madjid, dan Muhamad Wahyuni Nafis. Islam agama kemanusiaan: membangun tradisi dan visi baru Islam Indonesia. Jakarta: Dian Rakyat, 2010.

Rendo bangku Koto Gadang. Guguk Malintang, Padangpanjang Timur, Padangpanjang, Sumatera Barat: ISI Padangpanjang, 2016.

Sachari, Agus. Estetika. Bandung: Penerbit ITB, 2002.

Saleh, Fauzan. Modern trends in Islamic theological discourse in 20th century Indonesia: a critical study. Social, economic, and political studies of the Middle East and Asia, v. 79. Leiden ; Boston: Brill, 2001. 
Sarumpaet, Riris K., ed. Sastra masuk sekolah. Cet. 1. Magelang: IndonesiaTera, 2002.

Sondakh, A. J., Richard A. D. Siwu, dan Reiner Emyot Ointoe. Si tou timou tumou tou =: Manusia hidup untuk memanusiakan manusia: refleksi atas evolusi nilai-nilai manusia. Cet. 2. Jakarta: Pustaka Sinar Harapan, 2003.

Syukur, M. Amin. Teologi Islam terapan: upaya antisipatif terhadap hedonisme kehidupan modern. Solo: Tiga Serangkai Pustaka Mandiri, 2003.

Tangkilisan, Yuda B., M. Iskandar, dan Indonesia, ed. Penulisan sejarah: pemikir kebudayaan. Cet. 1. Jakarta: Direktorat Nilai Sejarah, Direktorat Jenderal Sejarah dan Purbakala, Kementerian Kebudayaan dan Pariwisata, 2010.

Widjojo, Muridan S., dan Mashudi Noorsalim, ed. Bahasa negara versus bahasa gerakan mahasiswa: kajian semiotik atas teks-teks pidato Presiden Soeharto dan selebaran gerakan mahasiswa. Cetakan pertama. Jakarta: LIPI Press, 2004.

Yudiono K. S. Pengkajian kritik sastra Indonesia. Jakarta: Gramedia Widiasarana Indonesia, 2009.

Yuhasnil, Yuhasnil. "Perubahan Nilai Nilai Budaya Dalam Proses Modernisasi Di Indonesia." Menara Ilmu 13, no. 5 (14 April 2019). https://doi.org/10.33559/mi.v13i5.1375. 